\title{
Investigation into Heat Treatment and Residual Stress in Laser Clad AA7075 Powder on AA7075 Substrate
}

\author{
R. Cottam $\cdot$ V. Luzin $\cdot$ Q. Liu $\cdot$ Y. C. Wong $\cdot$ \\ J. Wang • M. Brandt
}

Received: 30 January 2013/Revised: 24 March 2013/Accepted: 24 May 2013/Published online: 4 June 2013

(C) Springer Science+Business Media New York and ASM International 2013

\begin{abstract}
The laser cladding of AA7075 powder onto a AA7075 substrate was conducted to evaluate the effect of heat treatment and to measure residual stress between the clad layer and substrate to better understand the effect of laser cladding. The microstructure formed in the clad region was characteristic of a high cooling rate, which is typical for laser cladding. The heat-affected zone (HAZ) showed coarser precipitates when compared with the substrate and was attributed to the heating from the laser. A solution heat treatment followed by aging was employed to restore the strength in the HAZ. Nanohardness traverses of the clad and substrate was performed and it was shown the hardness in the 7075 clad layer was lower than the substrate both pre- and post-heat treatment and was attributed to the vaporization of zinc and magnesium. Neutron diffraction was employed to measure the residual stress both
\end{abstract}

R. Cottam $(\varangle) \cdot$ Y. C. Wong · J. Wang

Industrial Laser Applications Laboratory, IRIS, Faculty

of Engineering and Industrial Sciences, Swinburne University

of Technology, Melbourne, VIC 3122, Australia

e-mail: rcottam@swin.edu.au

R. Cottam - Q. Liu · Y. C. Wong · M. Brandt

Defence Materials Technology Centre, Hawthorn, VIC 3122,

Australia

V. Luzin

ANSTO, Lucas Heights, NSW 2232, Australia

Q. Liu

Defence Science and Technology Organisation, Fishermans

Bend, VIC 3207, Australia

M. Brandt

School of Aerospace, Mechanical and Manufacturing Engineering, RMIT University, P.O. Box 71, Bundoora, VIC 3083, Australia before and after heat treatment. The residual stresses formed in the clad layer were tensile and about $50 \mathrm{MPa}$ in magnitude; heat treatment increased the stress level to approximately $100 \mathrm{MPa}$.

Keywords AA7075 - Laser cladding - Residual stress · Neutron diffraction

\section{Introduction}

Today, the cost of ownership of complex machines is often as much as their purchase price and methods to reduce this cost are becoming attractive to organizations operating them. Repair of components worn or corroded during the machine life, instead of replacement, offers the potential for significant cost savings, particularly on components that involve relatively complex processes for their manufacture. Laser cladding is a deposition technology that is finding applications as a repair technology for a range of components such as jet engines, both titanium [1] and nickelbased superalloys [2], the repair of dies [3] and steam turbine blades [4]. The laser cladding repair of high strength aluminum alloy-based components, however, is an area that has received limited attention considering the range of components manufactured from these alloys employed on current and planned for next generation military aircraft.

Laser cladding is a process wherein a high power laser is used to melt a small region on a metallic substrate into which either a powder or wire is fed to build up a new layer. The composition of the powder can be the same as the substrate to rebuild a surface, or of a different composition to enhance the surface properties of a component. Typically, wear-resistant coatings [5] or corrosion-resistant 
coatings [6] are clad to enhance the surface characteristics. The process is complicated due to the interaction of many variables [7] including the laser power setting, the traversing speed, the amount of powder or wire being fed into the melt pool and the overlap distance between clad tracks.

The laser cladding of aluminum alloys with aluminum powder [8-12] has shown that there are several processing difficulties. These include liquation cracking, hydrogenbased porosity, high reflectivity of the laser radiation, and a high thermal diffusivity, which result in large laser power levels during processing and difficulty in controlling dilution and the size of the heat-affected zone (HAZ). While these issues can be overcome with close control over cladding parameters and preparation of the powder and substrate prior to cladding the mechanical properties of laser clad aluminum alloys are relatively unknown. A repair technique not only has to restore the dimension of the component but also the new layer needs to meet the original specification of the component. This includes mechanical properties and fatigue life for many components and the influence of residual stress. Therefore, an evaluation of the microstructure produced and its mechanical properties is required, including the measurement of residual stress for fatigue applications. The microstructural effect and mechanical properties of laser clad AA7075 alloys is not well documented.

This article evaluates the mechanical properties and residual stresses after laser cladding AA7075 aluminum alloy powder onto AA7075 substrate. Solution heat treatment and aging after laser cladding were investigated to understand their influence on both the mechanical properties and the residual stress state. This information will be used in the development of a repair technique for 7075 aluminum alloys.

\section{Experimental}

Laser cladding was performed with a $2.5 \mathrm{~kW}$ Nd:YAG laser. The laser was delivered with a 0.6-mm-diameter step index optical glass fiber terminated with collimating and focussing lenses of $200 \mathrm{~mm}$ focal length positioned to produce a Gaussian laser spot size of $3 \mathrm{~mm}$. The powder was delivered with a side injecting nozzle positioned perpendicular to the laser beam movement and in line with the laser spot. A schematic of the process is shown in Fig. 1. An aluminum 7075-T6 plate, $300 \times 300 \mathrm{~mm}$ by $6.25 \mathrm{~mm}$ thick was used as the substrate. The surface was grit blasted just prior to cladding to remove surface oxides and other forms of contamination. The clad layer was formed by a raster of $30 \mathrm{~mm}$ with a $0.3-\mathrm{mm}$ inter-track spacing. The raster was complete after $30 \mathrm{~mm}$ length of clad layer was formed. This was repeated for three successive layers to produce a clad of $3 \mathrm{~mm}$. The AA7075 powder had a particle size ranging between 50 and $100 \mu \mathrm{m}$. Laser cladding was conducted at a traversing speed $32 \mathrm{~mm} / \mathrm{s}$ and incident power of 2,500 $\mathrm{W}$ on the work piece. The powder feed rate was $7 \mathrm{~g} / \mathrm{min}$ and argon was used as the shielding gas. These parameters were the result of successive trials of various traversing speeds and laser powers.

From the length of clad track, samples were cut parallel to the individual track direction for heat treatment. The heat treatment conducted was a solution heat treatment for $1.5 \mathrm{~h}$ at $490{ }^{\circ} \mathrm{C}$, followed by quenching in water and aging at $121{ }^{\circ} \mathrm{C}$ for $24 \mathrm{~h}$. Samples of the as-clad- and as-heattreated specimens were prepared for analysis via standard metallographic polishing to colloidal silica. Scanning electron microscopy (SEM) was performed on a field emission microscope to qualitatively evaluate the precipitate size of pre- and post-heat treatment. Energy dispersive $\mathrm{X}$-ray spectroscopy (EDS) was also conducted to analyze the composition of the second phase particles present in the microstructures. The samples were then etched using Keller's reagent and viewed under a light microscope. Nanoindentation hardness with a Berkovich indenter was measured along the clad layer, for both as-clad- and as-heat-treated samples.

To better understand the severity of the laser processing on the final stress state, the residual stress was measured using neutron diffraction analysis. A monochromatic neutron beam with $\lambda=1.727 \AA$ and diffraction from $\mathrm{Al}\{311\}$ reflections were used for the strain analysis of the samples. The combination of aluminum $\{311\}$ lattice spacing

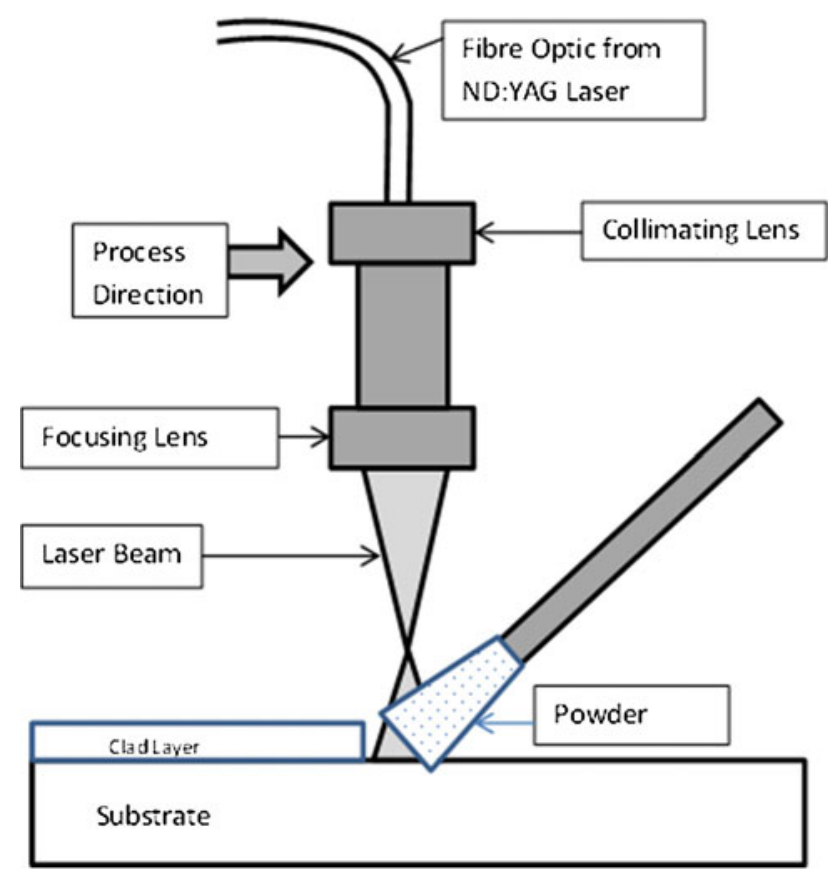

Fig. 1 Process schematic for laser cladding 
$\left(d_{311} \sim 1.36 \AA\right)$ and the wavelength resulted in a scattering angle of $90^{\circ}$, providing the best spatial resolution and the instrument configuration to be close to optimal in regard to the beam intensity. For the neutron strain measurements, a sampling volume with nominal size of $0.4 \times 0.4 \times 18 \mathrm{~mm}^{3}$ was used. This spatial resolution was sufficient to perform through thickness scans at $\sim 20$ different depths at the same time, providing good accuracy of strain measurements of 60-70 $\mu$ strains that resulted in a stress accuracy of $\sim 5 \mathrm{MPa}$. Neutron diffraction data was collected for three perpendicular directions (two perpendicular in-plane direction and one normal), enabling to resolution of in-plane stresses and the unstrained lattice parameter $d_{0}$. To calculate stresses from strains, Hook's law was used with elastic constants $\mathrm{E}\{311\}=71.3 \mathrm{GPa}$ and $v\{311\}=0.354$. The frame of the sample, which could not be measured, is expected to be in compression and thus provides the stress balance for the sample.

\section{Results}

Figure 2 shows that in the as-clad and heat-treated state, the microstructure in the clad layer consists of predominantly equiaxed grains. SEM images of the clad layers, Fig. 3, show that the AA7075 clad layer had a uniform distribution of second phase particles; heat treatment reduced the number of particles present. EDS was performed on the particles in the as-clad and heat-treated states, Fig. 4. From these spectra, it is apparent that in the as-clad layer there is a high content of copper, magnesium, and zinc, which is consistent with $\eta$ phase. Following heat treatment, iron was detected, indicating that the insoluble constituent phase $\mathrm{Al}_{7} \mathrm{Cu}_{2} \mathrm{Fe}$ has formed [13].

The HAZ that formed as a result of laser cladding process is shown in Fig. 5 for both pre- and post-heat treatment samples. It is apparent that fine precipitates are present in this zone due to the cladding process; after heat treatment, these precipitates are not visible in the SEM images. The $\eta^{\prime}$ phase that forms after heat treatment is usually imaged with transmission electron microscopy; their size makes them unresolvable in the SEM. However, these images illustrate that precipitate size is increasing due to the laser cladding and is then reduced during the heat treatment process.

Nanoindentation hardness was measured to evaluate the change in mechanical properties through the section of the clad in the as-clad and as-heat-treated conditions, see Fig. 6. Nanoindentation hardness was selected over microhardness due to its higher spatial resolution, which was required to identify the change in mechanical properties within the HAZ. From this data, it is apparent that the heat treatment increases the strength of both the clad layer
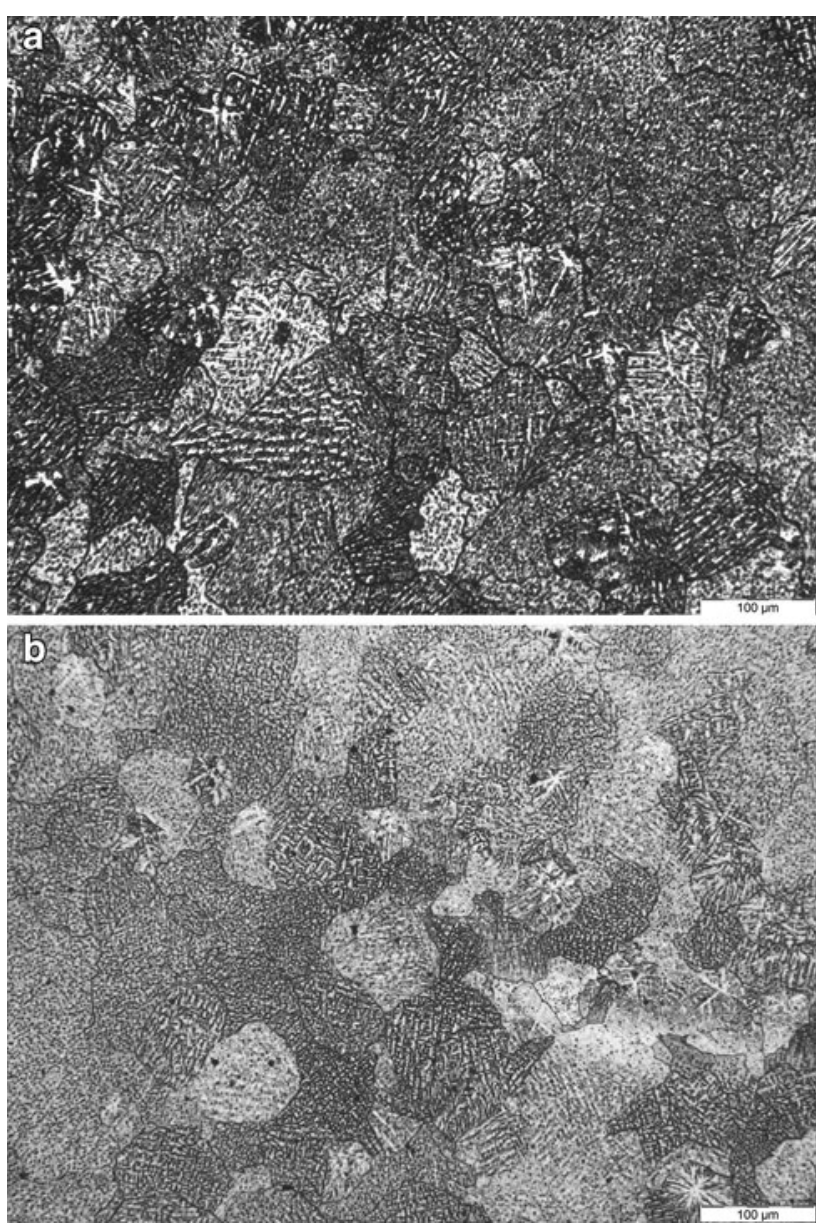

Fig. 2 Optical microstructures of clad layer: (a) as-clad 7075; (b) heat-treated 7075

and the substrate. It was observed that the hardness in the clad layer for 7075 is lower than the hardness in the substrate. To better understand this result, the composition of the clad layer, the substrate and the powder used for the cladding were analyzed, Table 1 . The concentration of zinc and magnesium in the cladding layer is lower than the concentration in both the substrate and the powder. It should also be noted that the iron level in the powder is higher than the substrate; these results will be discussed further in a subsequent section.

Critical to the accuracy of the neutron diffraction measurement of the residual stress is the value used for the unstrained lattice parameter $\left(d_{0}\right)$. It is well known in the literature that the precipitation state has an influence on the unstrained lattice parameter [14-16]. The variation in the unstrained lattice parameter as a function of position for the as-clad sample is shown in Fig. 7.

The residual stresses that formed in the clad layer, measured both before and after heat treatment, are shown in Fig. 8. The stress levels in the as-clad samples are low in both orientations. In the orientation parallel to the track 

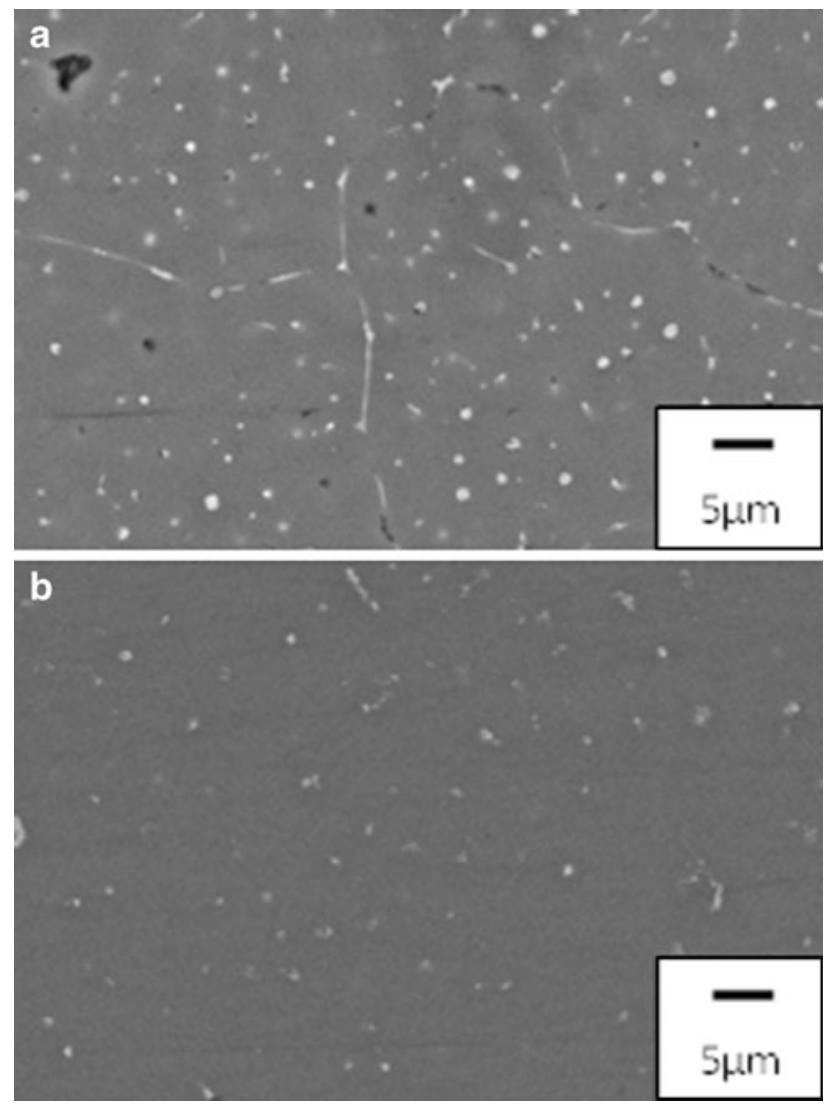

Fig. 3 SEM, secondary electron image of clad layer prepared with a cladding speed of $1,900 \mathrm{~mm} / \mathrm{min}$ and a power of $2,500 \mathrm{~W}$, with a Gaussian spot size of $3 \mathrm{~mm}$, taken parallel to the individual track directions: (a) as-clad 7075; (b) heat-treated 7075

direction, there is a small variation in the residual stresses. The clad layer shows a low level of a compressive stress, which moves to a slight tensile stress at the interface. It then decreases and rises again further into the substrate. The range of stress is only $50 \mathrm{MPa}$. After heat treatment, the samples show an increase in the tensile stress to $100 \mathrm{MPa}$ where the center is in tension and the outer regions are in compression, which is characteristic of a quenching stress [17]. Due to the thickness of the clad layer being much smaller that the width of the sample, the stress normal to the clad layer is assumed to be zero and as such the $\sin ^{2} \psi$ was employed to calculate the $d_{0}$ spacing.

\section{Discussion of Results}

The microstructure of the AA7075 clad region in the as-clad condition shows an equiaxed microstructure with large $\eta$ phase particles (Fig. 1). After the heat treatment, there exist a number of fine particles, which have measurable iron contents. This phase is the insoluble $\mathrm{Al}_{7} \mathrm{Cu}_{2} \mathrm{Fe}$. The iron content of the powder (Table 1) is higher than that
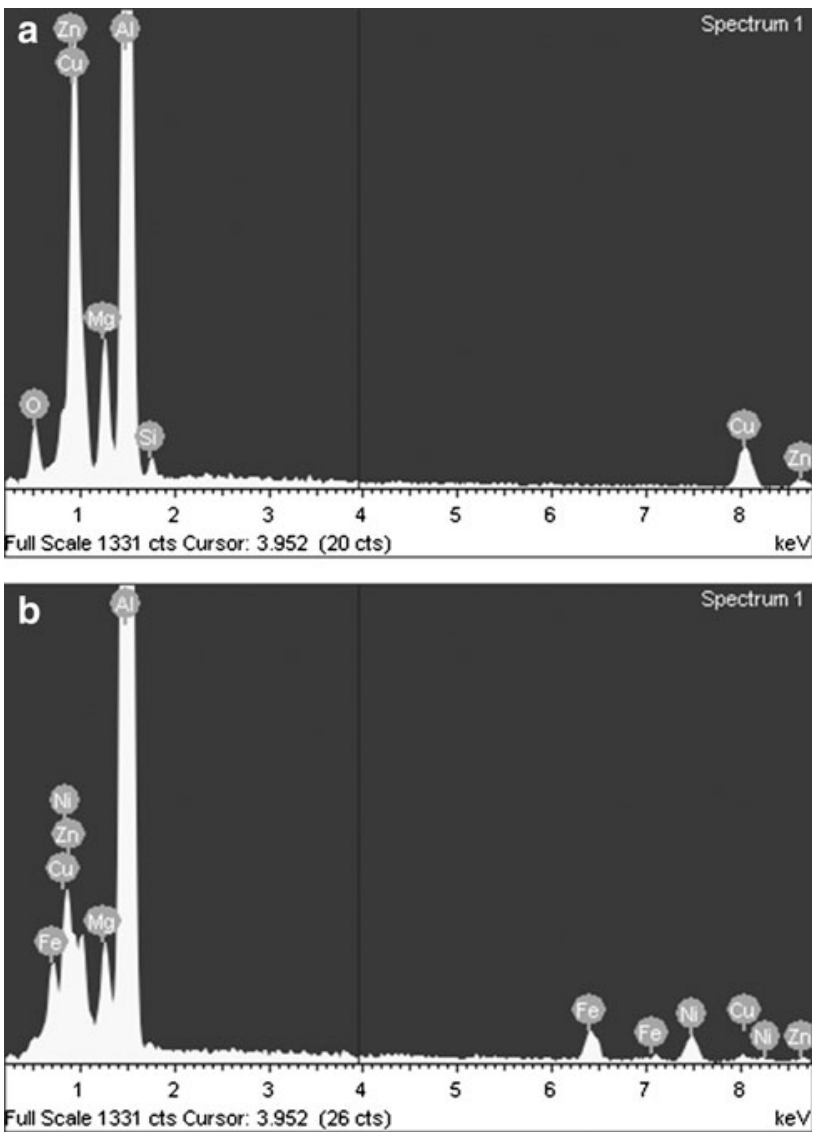

Fig. 4 EDX spectrum for second phase particles in AA7075: (a) as-clad; (b) after heat treatment

of the substrate, which results in an increase in the iron content of the clad layer and the increased number of precipitates in the heat-treated condition compared with the substrate. The composition of the clad and substrate also shows that the zinc and magnesium content has decreased. When considering that these two elements have a low vaporization point, it is reasonable to assume that the reduction in the concentration of these alloying elements in the clad layer is due to vaporization. This reduction in the alloying elements reduces the volume of the $\eta^{\prime}$ strengthening phase during the aging treatment and is responsible for the lower hardness in the clad region [11]. The increase in strength brought about by the heat treatment can be explained by the coarser particles in the clad and HAZ being dissolved and then re-precipitated as a finer more dispersed $\eta^{\prime}$ phase.

The lattice parameter in the clad layer (right of the interface, Fig. 7) is smaller than that of the substrate. Considering that if both $\mathrm{Zn}$ and $\mathrm{Mg}$ are in solution, the lattice parameter will increase; the low value of the lattice spacing suggests that the clad layer is in the over-aged state. Close to the interface, the lattice parameter increases. Given that this alloy naturally ages, and that the 
measurement of the samples was performed 3 months after producing the samples; the increase in lattice parameter is likely due to the formation of the $\eta^{\prime}$ phase [16]. The lattice parameter value decreases at approximately $2 \mathrm{~mm}$ beyond the interface.

The effect of heat treatment on the precipitation state is complicated. Dumont et al. explained the effect of heat using Nicolas and Deschamps theory [18], where the heat
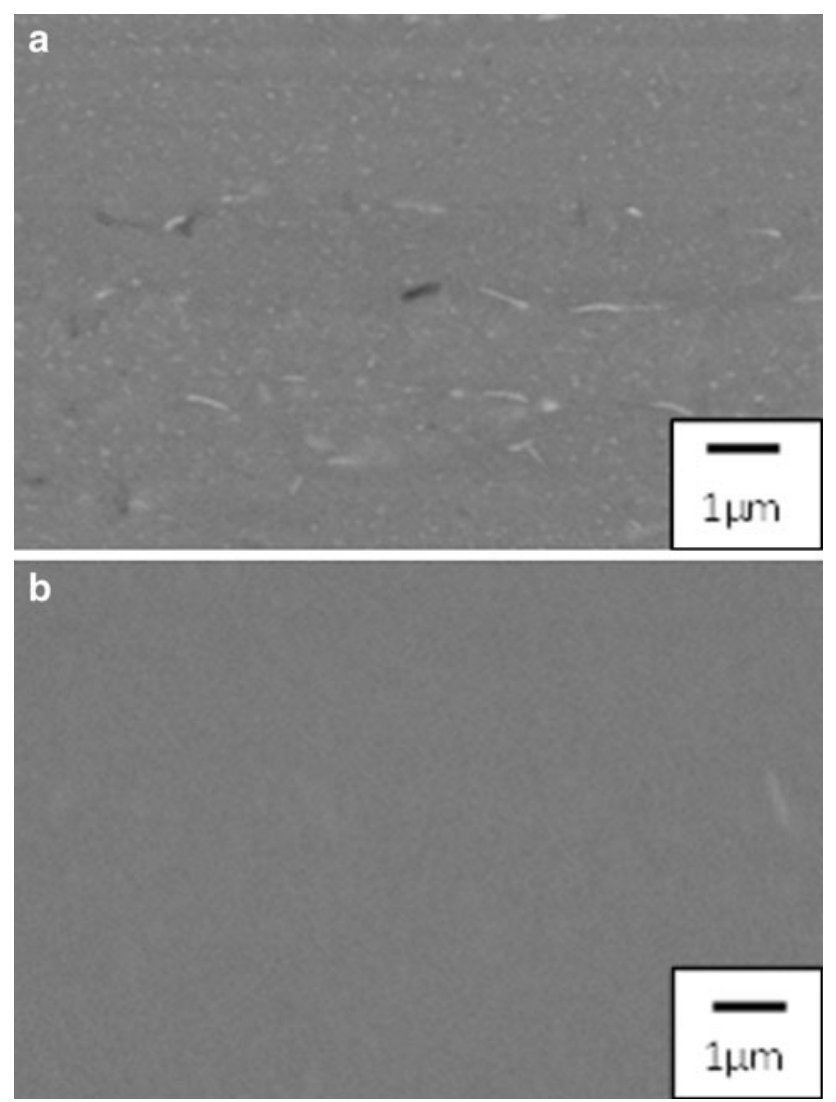

Fig. 5 SEM, secondary electron image of heat-affected zone due to laser cladding: (a) as-clad; (b) heat-treated from the laser causes the small particles to go into solution first due to their smaller dissolution time; the larger particles require longer times, and hence there is no change in the mean size of precipitates after the cladding has finished. The time spent at temperature is too short for coarsening of precipitates. However, during natural aging, the remaining precipitates coarsen, causing the lattice parameter to decrease, hence the lower values observed in the substrate.

At the time of processing, the alloying elements within the clad region will be in solution and the HAZ will also have significant amount of $\mathrm{Zn}$ and $\mathrm{Mg}$ in solution [17], and therefore the material is quite soft. Coupled with the

Table 1 Composition of the three components in the AA7075 clad layer

\begin{tabular}{llllllll}
\hline Samples & $\mathrm{Al}$ & $\mathrm{Si}$ & $\mathrm{Cu}$ & $\mathrm{Fe}$ & $\mathrm{Mg}$ & $\mathrm{Zn}$ & $\mathrm{Cr}$ \\
\hline Substrate & $\mathrm{Bal}$ & 0.06 & 1.41 & 0.19 & 2.43 & 5.52 & 0.24 \\
Powder & $\mathrm{Bal}$ & 0.16 & 1.55 & 0.27 & 2.56 & 5.49 & 0.21 \\
Clad & $\mathrm{Bal}$ & 0.1 & 1.44 & 0.24 & 2.15 & 4.53 & 0.24 \\
\hline
\end{tabular}

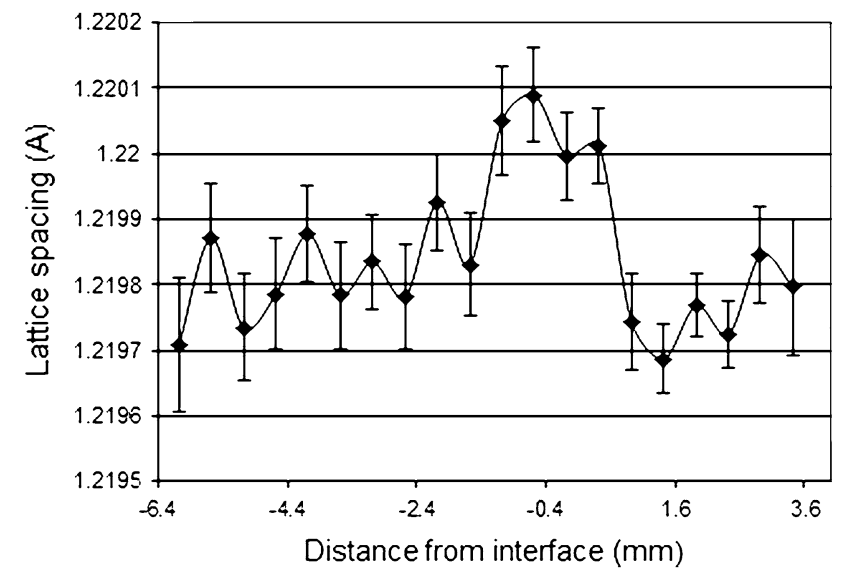

Fig. 7 Lattice spacing, $d_{0}$, in the as laser clad AA7075, calculated using the $\sin ^{2} \Psi$ method
Fig. 6 Nanohardness traverses pre- and post-heat treatment for AA7075 clad layer

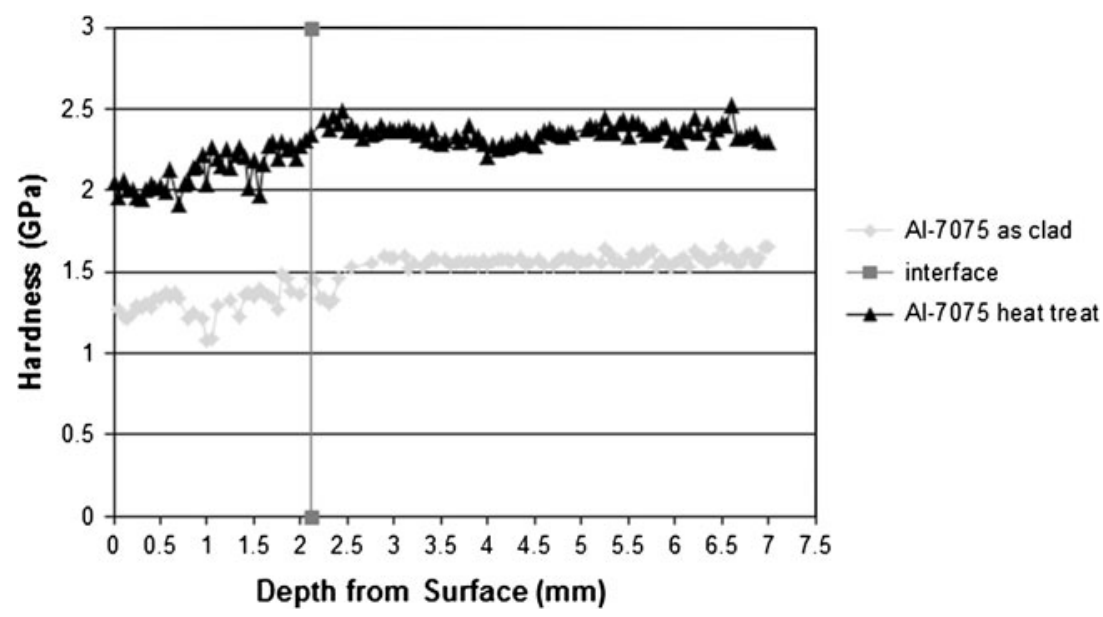


Fig. 8 Residual stress profiles for the AA7075 clad layer:

(a) substrate; (b) as-clad;

(c) heat-treated
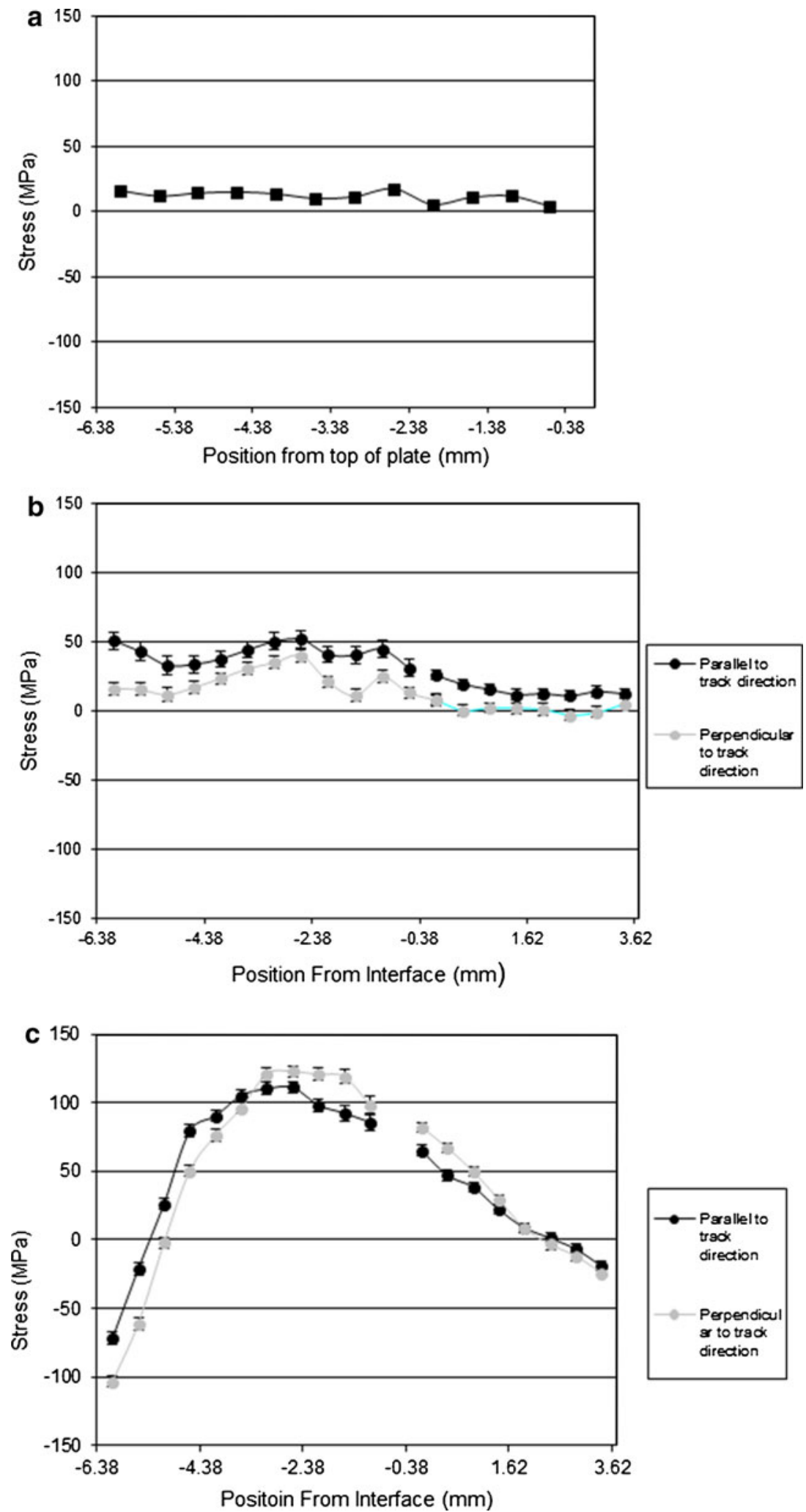

elevated temperatures, the material would have a yield strength that is low and therefore instead of retaining the stresses that form, plastic deformation occurs [19]. This is supported by the fact that the hardness after cladding is lower that the hardness after heat treatment. Linton and Ripley [16] have shown that natural age hardening in friction stir welds of AA7075 results in a decrease in the residual stress measured. Therefore, the final stress state of 
a majority of the HAZ and clad layer is low level tensile, which in part can be attributed to the natural aging process. The formation of residuals stress due to laser cladding is mainly due to the thermal profile created by laser heating the substrate during processing [20]. The thermal profile generates stress by the colder areas constraining the hotter areas. As aluminum does not undergo a phase transformation during cooling, the thermal profile makes the main contribution to the residual stress levels formed.

After heat treatment, the residual stress profile shows compression at the surface and tension in the center. This is characteristic of a quenching stress where the surface cools faster than interior of the sample. Therefore, it is the quench associated with the solution heat treatment stage of the heat treatment that is responsible for the increase in stress after the heat treatment. The fact that this stress is higher than the laser clad residual stress profile was due to the conditions of the quench. After laser cladding, the samples were cut out from the 7075 plate which reduced their thermal mass. After the solution treatment, the samples were quenched in room temperature water, which when coupled with the small thermal mass, resulted in a fast quenching rate. It has been shown that the quenching rate significantly influences the residual stress formed [21], with larger tensile stresses resulting from higher quenching rates in aluminum alloys. Therefore, the high quenching rate of the solution heat treatment is responsible for the increase in tensile residuals stress. The residual stress formed in the laser clad layer is larger than that of the substrate, Fig. 8, which confirms that the quenching stage of the heat treatment is responsible for the increase in residual stress after heat treatment. Unfortunately, this cannot be avoided as this step is critical to the following aging heat treatment, which restores the strength in the HAZ. Typical stress relief heat treatments lower residual stresses; however, they are typically conducted at low homologous temperatures and do not involve quenching after heating [22].

\section{Conclusion}

The microstructure in the clad zone was non-equilibrium and was attributed to the high cooling rates of the process. Post cladding heat treatment restored the strength in the HAZ and for the 7075 alloy in the clad layer. The hardness in the clad layer for 7075 clad was lower that the substrate; this was attributed to the vaporization of the zinc and magnesium during processing. The residual stress in the asclad condition was low and attributed to the softening of the alloy during processing. The heat treatment resulted in an increase in the residual stress with a profile characteristic of a quenching stress and was attributed to quench in the solution heat treatment.
Acknowledgments The authors would like to thank the Defence Materials Technology Centre (DMTC) for funding this study through Program 4, "Propulsion Systems," Project 4.1 "Repair technologies for current and next generation aircraft systems." The authors would also like to thank Girish Thipperudrappa for his help with conducting the laser cladding experiments.

\section{References}

1. R.H. Richter, S. Orban, S. Nowotny, Laser cladding of the titanium alloy Ti6242 to restore damaged blades, in Proceedings of the 23rd International Congress on Applications of Lasers and Electro-optics (2004)

2. I. Tabernero, A. Lamikiz, S. Martinez, E. Ukar, J. Figueras, Evaluation of the mechanical properties of Inconel 718 components built by laser cladding. Int. J. Mach. Tools Manuf. 51, 465-470 (2011)

3. J.Y. Chen, K. Conlon, L. Xue, R. Rogge, Experimental study of residual stresses in laser clad AISI P20 tool steel on pre-hardened wrought P20 substrate. Mater. Sci. Eng. A 527, 7265-7273 (2010)

4. N. Alam, Extended service life and reliability for steam turbine components. Weld World 53(special issue), 107-112 (2009)

5. A. Frenk, M. Vandyoussefi, J.-D. Wagniere, A. Zryd, W. Kurz, Analysis of the laser-cladding process for stellite on steel. Metall. Mater. Trans. B 28, 501-508 (1997)

6. I. Hemmati, V. Ocelik, M.T.M. De Hosson, Microstructral characterisation of AISI 431 martensitic stainless steel laser deposited coatings. J. Mater. Sci. 46, 3405-3414 (2011)

7. M. Picasso, C.F. Marsden, J.-D. Wagniere, A. Frenk, M. Rappaz, A simple but realistic model for laser cladding. Metall. Mater. Trans. B 25B, 281-291 (1994)

8. Y. Durandet, M. Brandt, Q. Liu, Challenges of laser cladding Al7075 alloy with Al-12Si alloy powder. Paper presented at the ICAMP 3, 2004

9. Y. Durandet, R. Deam, P. Bendeich, M. Ripley, M. Brandt, Q. Liu, P. Baburamani, Residual stress in A17075 alloy plate laser clad with Al-12Si alloy powder. Paper presented at the Pacific international conference on application of lasers and optics, 2006

10. Y. Durandet, P. Kallage, M. Brandt M, Control of dilution during laser cladding of Al7075 substrates with $\mathrm{Al}-12 \% \mathrm{Si}$ aluminium alloy powder. Paper presented at the Pacific international conference on application of lasers and optics, 2004

11. C.G. Pickin, S.W. Williams, P. Prangnell, C. Derry, M. Lunt, Control of weld composition when arc welding high strength aluminium alloys using multiple filler wires. Sci. Technol. Weld. Join. 15, 491-496 (2010)

12. Q. Liu, P.K. Sharp, M. Brandt, Y. Durandet, Effects of process parameters on the quality of laser cladding of 7075-T6 aluminium alloy with $\mathrm{Al}-\mathrm{Si}$ powder. Paper presented at the Pacific international conference on application of lasers and optics, 2004

13. J.-Q. Su, T.W. Nelson, R. Mishra, M. Mahoney, Microstructural investigation of friction stir welded 7050-T651 aluminium. Acta Mater. 51, 713-729 (2003)

14. A. Steuwer, M. Peel, P.J. Withers, Dissimilar friction stir welds in AA5083-AA6082: the effect of process parameters on residual stress. Mater. Sci. Eng. A 441, 187-196 (2006)

15. A. Steuwer, M. Dumont, M. Peel, M. Preuss, P.J. Withers, The variation of the unstrained lattice parameter in an AA7010 friction stir weld. Acta Mater. 55, 4111-4120 (2007)

16. V.M. Linton, M.I. Ripley, Influence of time on residual stresses in friction stir welds in agehardenable $7 \mathrm{xxx}$ aluminium alloys. Acta Mater. 56, 4319-4327 (2008)

17. W.J.J. Vorster, A.M. Korsunsky, Analysis of residual strain and stress states due to heat treatment and thermal processing. J. Strain Anal. 44, 71-90 (2009) 
18. M. Nicolas, A. Deschamps, Characterisation and modelling of precipitate evolution in an $\mathrm{Al}-\mathrm{Zn}-\mathrm{Mg}$ alloy during non-isothermal heat treatments. Acta Mater. 51, 6077-6094 (2003)

19. M.T. Hutchings, P.J. Withers, T.M. Holden, T. Lorentzen, Introduction to the Characterisation of Residual Stress by Neutron Diffraction (Taylor and Francis, London, 2005)

20. U.O.B. de Oliveira, V. Ocelik, J.T.M. de Hosson, Residual stress analysis in Co-based laser clad layers by laboratory X-rays and synchrotron diffraction techniques. Surf. Coat. Technol. 201, 533-542 (2006)

21. D.A. Tanner, J.S. Robinson, Residual stress magnitudes and related properties in quenched aluminium alloys. Mater. Sci. Technol. 22, 77-85 (2006)

22. J. Chen, S.-H. Wang, L. Xue, On the development of microstructures and residual stresses during laser cladding and postheat treatments. J. Mater. Sci. 47, 779-792 (2012) 